Check for updates

Cite this: RSC Adv., 2019, 9, 18165

Received 10th May 2019

Accepted 1st June 2019

DOI: $10.1039 / \mathrm{c} 9 \mathrm{ra03526e}$

rsc.li/rsc-advances

\title{
Determination of the absolute configuration of conformationally flexible molecules by simulation of chiro-optical spectra: a case study $\dagger$
}

\author{
Michele Mancinelli, (DD a Roberta Franzini, (DD ${ }^{\mathrm{b}}$ Andrea Renzetti, ${ }^{\mathrm{c}}$ Emanuela Marotta, (D) ${ }^{\mathrm{a}}$ \\ Claudio Villani (iD *b and Andrea Mazzanti (D)*a
}

\begin{abstract}
The assignment of the absolute configuration (AC) of two conformational flexible organic molecules by means of TD-DFT simulation of the electronic circular dichroism (ECD) spectra is presented. The factors leading to a reliable assignment were evaluated in the various steps of the process. The effects of different functionals and basis sets in the geometry optimization step is very limited in terms of the resulting optimized geometries, whereas the inclusion of the solvent in the calculations has a much larger effect on the correct evaluation of the conformational ratio. B3LYP and M06-2x were found to be the most accurate functionals for geometry optimization. CAM-B3LYP and $\omega B$ B7X-D provided the best results in the TD-DFT simulations.
\end{abstract}

\section{Introduction}

The determination of the absolute configuration (AC) of synthetic molecules and natural products is still one of the most challenging tasks in organic chemistry. Since the first experimental determination from Bijovet, ${ }^{1}$ the anomalous dispersion X-ray technique has been the most widely used approach to determine the AC of organic molecules. This methodology, although based on experimental data, is not free from pitfalls and drawbacks. ${ }^{2}$ Over the decades, the availability of this technique has been widened by the use of $\mathrm{Cu}-\mathrm{K} \alpha \mathrm{X}$-ray sources, that allow a reliable determination of $\mathrm{AC}$ also in those molecules missing heavy atoms, ${ }^{3}$ such as many natural compounds. However, the primary obstacle to the use of X-ray diffraction is still the preparation of good single crystals, which in many cases is impossible or unfeasible due to the limited amount of compound.

Thanks to the development of computational methods, the assignment of the AC by the quantum-mechanical simulation of chiro-optical spectra has become a "classical" alternative to the X-ray methodology. In the past few years, the simulation of optical rotatory dispersion (ORD), electronic circular dichroism

\footnotetext{
${ }^{a}$ Department of Industrial Chemistry "Toso Montanari”, University of Bologna, Viale Risorgimento 4, 40136-Bologna, Italy.E-mail: andrea.mazzanti@unibo.it

${ }^{b}$ Dipartimento di Chimica e Tecnologie Del Farmaco, Sapienza Università di Roma, P.le A. Moro 5, 00185 Roma, Italy. E-mail: Claudio.villani@uniroma1.it

${ }^{c}$ Faculty of Education, Room 426, University of the Ryukyus, 1 Senbaru, Nishihara, Okinawa 903-0213, Japan

$\dagger$ Electronic supplementary information (ESI) available: Fig. S1-S31, computational details. CCDC 1897062 and 1897063. For ESI and crystallographic data in CIF or other electronic format see DOI: 10.1039/c9ra03526e
}

(ECD) and vibrational circular dichroism (VCD) spectra have allowed the determination of the $\mathrm{AC}$ of a wide typology of organic molecules. ${ }^{4}$ Some operative protocols have been formalized ${ }^{5}$ and methods have been devised to evaluate the reliability of the various simulations. ${ }^{6}$

Within the time-dependent DFT (TD-DFT) method for the simulation of the ECD spectra, many combinations of DFT functionals and basis set have been used for the various steps of the AC assignment. Some benchmark studies have been performed on the TD-DFT simulation of the UV spectra of small molecules, ${ }^{7}$ organic dyes ${ }^{8}$ and metal complexes. ${ }^{9}$ Here we present a case study on two diastereomeric, highly flexible, organic molecules with few UV-chromophoric groups, in which we evaluate in details the performance of various combination of functionals and basis sets in the conformational analysis step, by comparison with experimental NMR data. The performance of TD-DFT with different functionals and basis sets is also performed to investigate the key factors that lead to a reliable interpretation of the chiro-optical spectra.

\section{Results and discussion}

Compounds $\mathbf{1 a}+\mathbf{2 a}$ and $\mathbf{1 b}+\mathbf{2 b}$ (Scheme 1) were prepared by a single reaction according to a reported procedure. ${ }^{10}$ Due to the reaction conditions employed, the presence of the two stereocenters forged during the reaction entails the formation of four stereoisomers. The two diastereoisomeric pairs can be easily converted into each other by treatment with a base, due to the high acidity of the acetoacetate proton, ${ }^{11}$ yielding an equilibrium ratio of $70: 30$ (in ethanol at $+25^{\circ} \mathrm{C}$ ). The four stereoisomers resulting from the reaction were resolved by chiral 
<smiles>COC(=O)[14C](Sc1c[nH]c2cc(Cl)ccc12)C(C)=O</smiles><smiles>COC(=O)[Te](C(C)=O)S(=O)c1c[nH]c2cc(Cl)ccc12</smiles>
Base $\downarrow \uparrow$<smiles>COC(=O)P(C(C)=O)c1c[nH]c2cc(Cl)ccc12</smiles>

1b
Base $\downarrow \uparrow$<smiles>COC(=O)[Te](C(C)=O)c1c[nH]c2cc(Cl)ccc12</smiles>

minor

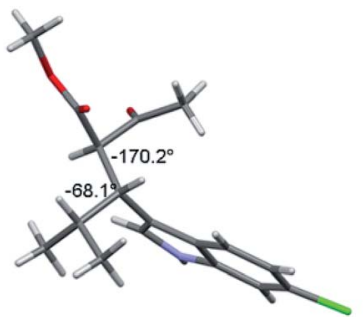

$1 \mathrm{a}$

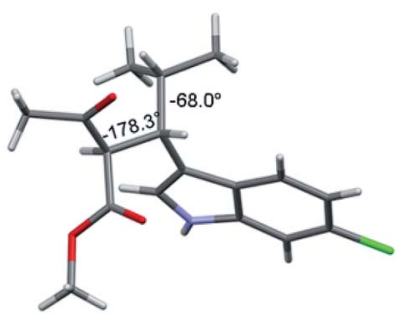

$2 b$

Fig. $2 \mathrm{X}$-ray structure of compounds $1 \mathrm{a}(2 R, 3 R)$ and $2 \mathrm{~b}(2 R, 3 S)$. The numbers indicate the dihedral angles between the $\mathrm{H} 2$ and $\mathrm{H} 3$ hydrogens, and between $\mathrm{H} 3$ and $\mathrm{H} 4$.

right) crystallized by slow evaporation (10 days) from an acetonitrile solution in the same $P 2_{1} 2_{1} 2_{1}$ space group, and the $2 R, 3 S$ $\mathrm{AC}$ was assigned (Flack parameter $=0.04$ ). $\$$ Being $2 \mathrm{~b}$ the enantiomer of $\mathbf{1 b}$, the absolute configuration of $\mathbf{1 b}$ is therefore $2 S, 3 R$, in agreement with the base-catalyzed mechanism of diastereomerization. An analogous reasoning applies to $\mathbf{2 a}$ (enantiomer of 1a), whose AC is $(2 S, 3 S)$.

(Fig. 1).

ECD detection allowed to confirm that the two major peaks are enantiomers (1a and $\mathbf{2 a}$ ), as well are the minor ones ( $\mathbf{1 b}$ and 2b). A chemical correlation followed by CSP-HPLC in the presence of $\mathrm{Et}_{3} \mathrm{~N}$ as base allowed to determine that the second eluted peak 1b converts into the first eluted 1a (Fig. S1 in ESI†). Thus the first and the second peak are diastereoisomers (1a vs. 1b) with the same $\mathrm{AC}$ at the $\mathrm{C} 3$ carbon, and the same happens for the third and fourth eluted peaks (2b and $2 \mathbf{a}$, respectively).

Thanks to the presence of the chlorine, the absolute configuration of stereoisomers $\mathbf{1 a}$ and $\mathbf{2 b}$ (i.e., the minor stereoisomer of 2a, third eluted peak on CSP-HPLC) was determined by anomalous dispersion X-ray crystallography. ${ }^{12}$

Compound 1a (Fig. 2, left) crystallized by evaporation $(24 \mathrm{~h})$ from a chloroform solution in the $P 2_{1} 2_{1} 2_{1}$ chiral space group, and the $2 R, 3 R$ absolute configuration was assigned with Flack parameter $=0.03 .^{10}$ After many attempts, compound $2 \mathbf{b}$ (Fig. 2,

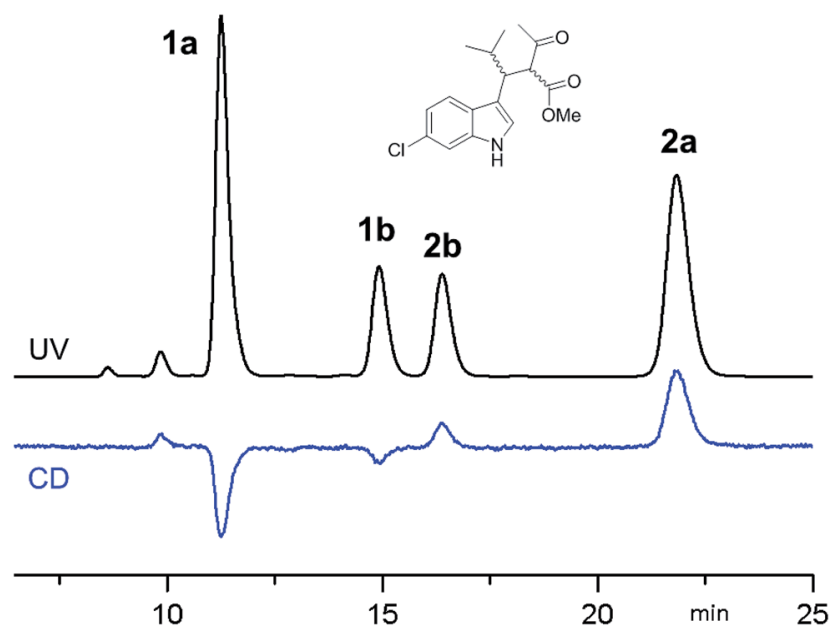

\section{NMR conformational analysis and dynamic behaviour}

Compounds 1a and $\mathbf{1 b}$ showed similar ${ }^{1} \mathrm{H}-\mathrm{NMR}$ spectra in terms of coupling constants. The $\mathrm{H} 2-\mathrm{H} 3{ }^{3} J$ coupling constant was $11.9 \mathrm{~Hz}$ for $1 \mathrm{a}$ and $11.3 \mathrm{~Hz}$ for $\mathbf{1 b}\left(\right.$ in $\mathrm{CD}_{3} \mathrm{CN}$ ), whereas the $\mathrm{H} 3-$ $\mathrm{CH}_{\mathrm{i}-\mathrm{Pr}}{ }^{3} \mathrm{~J}$ coupling constants were 3.9 and $4.7 \mathrm{~Hz}$, respectively. The very large values for the $\mathrm{H} 2-\mathrm{H} 3$ coupling suggest that most of the populated conformations have these hydrogens in an anti-relationship, with the dihedral angle close to $180^{\circ},{ }^{13}$ whereas the small coupling constant between $\mathrm{H} 3$ and $\mathrm{CH}_{\mathrm{i}-\mathrm{Pr}}$ suggests a predominant gauche arrangement. This outcome is in full agreement with the solid state structures (Fig. 2). Due to the steric hindrance of the isopropyl group and of the acetoacetate moiety, compounds $\mathbf{1 a}$ and $\mathbf{1 b}$ can be conformationally correlated to 1-naphthyl aryl-carbinols, which are known to generate two conformational diastereoisomers due to the restricted rotation of the $\mathrm{sp}^{2}-\mathrm{sp}^{3}$ bond (Scheme 2). ${ }^{14}$ This conformational preference can be conveniently described by the anti-periplanar $(a p)$ and syn-periplanar descriptors $(s p) .{ }^{15}$

Variable temperature NMR experiments on 1a allowed to freeze the rotational motion around the indole-C3 bond, and to determine that the $a p$ and $s p$ conformations are populated in a $90: 10$ ratio at $-100{ }^{\circ} \mathrm{C}$ (in $\mathrm{CDFCl}_{2}$, Fig. S2 in $\mathrm{ESI}^{\dagger}$ ), with an experimental $\Delta G^{\circ}=0.75 \mathrm{kcal} \mathrm{mol}^{-1}$, corresponding to a $78: 22$ ratio at $+25^{\circ} \mathrm{C}$. NOE spectra recorded at ambient temperature in $\mathrm{CD}_{3} \mathrm{CN}$ showed that saturation of the $\mathrm{H} 3$ signal yielded strong NOEs on the $\mathrm{H}^{\prime}{ }^{\prime}$ and $\mathrm{H}_{2}^{\prime}$ signals of the indole (Fig. S3 in ESI $\dagger$ ), it was confirmed that the ap and $s p$ conformations are both populated also in a polar solvent. Saturation of the COMe signal yielded similar NOEs on $\mathrm{H} 2$ and $\mathrm{H} 3$, thus suggesting that the

† CCDC 1897062 and 1897063 contains the crystallographic data, see ESI for details.

Fig. 1 CSP-HPLC separation of compounds $1 a, 1 b, 2 a$ and $2 b$ (Daicel Chiralpak IA, hexane/2-propanol $93: 7,1 \mathrm{~mL} \mathrm{~min}^{-1},+25^{\circ} \mathrm{C}$ ). Top: UV detection at $280 \mathrm{~nm}$. Bottom: ECD detection at $280 \mathrm{~nm}$. 


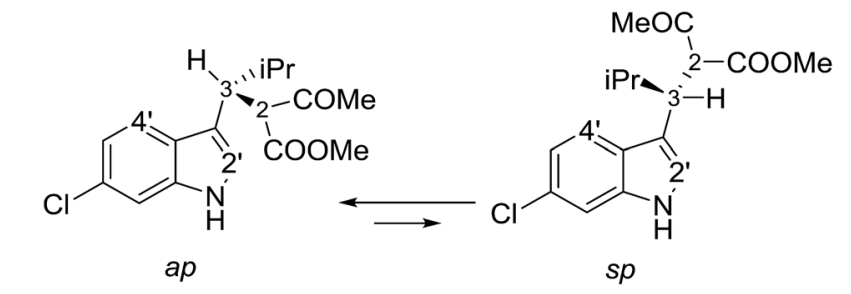

Scheme 2 The two available conformations of 1 a due to indole- $\mathrm{CH}$ rotation.

two conformations obtained by rotation of the COMe moiety are both populated. $\S$ In the case of $\mathbf{1 b}$, low temperature NMR spectra showed that the $a p / s p$ ratio was $94: 6$ at $-110{ }^{\circ} \mathrm{C}$ (Fig. S2 in $\mathrm{ESI} \dagger)$.

\section{Conformational analysis}

Because 1a and $\mathbf{1 b}$ are very flexible molecules, the conformational analysis step must consider a wide conformational space. The full conformational space was explored by molecular mechanics (MM) using the GMMX algorithm included in the Compute-VOA ${ }^{\mathrm{TM}}$ software, ${ }^{\boldsymbol{6} \boldsymbol{b}}$ as well as the MMFF force field, and retaining all the structures enclosed within a $10 \mathrm{kcal} \mathrm{mol}^{-1}$ range. A total of 66 energy minima were found for compound 1a. These conformations were then optimized using $\mathrm{B}^{3} \mathrm{LYP}^{16}$ and the $6-31 \mathrm{G}(\mathrm{d})$ basis set with the Gaussian 16 suite of programs. ${ }^{17}$ After DFT optimization some conformations were proved to be redundant, with only 50 geometries being really unique. All were checked to be true energy minima by frequency analysis (no imaginary frequencies were observed). Among these, 12 conformations were enclosed in $2 \mathrm{kcal} \mathrm{mol}^{-1}$ (Table 1 and Fig. S4 in ESI $\dagger$ ). Each conformation can be conveniently described by three main descriptors: (1) the H3-C2' dihedral angle, i.e., the angle between the benzylic $\mathrm{CH}$ and indole, that yields the $a p / s p$ conformations ( $\phi_{1}$ in Fig. 3 and Table 1); (2) the $\mathrm{H} 2-\mathrm{H} 3$ dihedral angle, i.e., the dihedral between the benzylic $\mathrm{CH}$ and the $\mathrm{CH}$ of the acetoacetate moiety $\left(\phi_{2}\right)$; and (3) the H3$\mathrm{H}_{\mathrm{i}-\mathrm{Pr}}$ dihedral angle between the benzylic $\mathrm{CH}$ and the isopropyl $\mathrm{CH}\left(\phi_{3} ; 3 \mathrm{D}\right.$ structures are reported in Fig. S4 of ESI $\left.\dagger\right)$.

The calculations results can be checked by the experimental NMR coupling constants and by low temperature spectra. Analysis of the data of Table 1 show that the most preferred conformation is the ap, where $\mathrm{H} 3$ is close to the $\mathrm{H} 4^{\prime}$ of indole (conf. \#1); this is the conformation observed in the solid state. Only three conformations have the $s p$ geometry, and the most stable one (\#19) is $1.29 \mathrm{kcal} \mathrm{mol}^{-1}$ above the global minimum, in agreement with low temperature NMR data. In nine conformations the $\mathrm{H} 2-\mathrm{H} 3$ dihedral angle is close to $|180|^{\circ}$, and the $\mathrm{H} 3-\mathrm{H} 4$ dihedral is close to $|60|^{\circ}$. Again this geometric preference is in agreement with the experimental ${ }^{3} J$ coupling constants in the ${ }^{1} \mathrm{H}$ NMR spectrum. However, conformations $\# 4, \# 8$, and \#33 are calculated at very low energy with respect to

$\S$ Although the rotation of the COMe is fast in the NMR timescale, the observed enhancements are the result of the weighted average of the NOEs of the populated conformations.
Table 1 Summary of the optimized conformations of 1a after MM conformational search and optimization by DFT at the B3LYP/6-31G(d) level. Relative energies in $\mathrm{kcal}_{\mathrm{mol}}^{-1}$

\begin{tabular}{lllllll}
\hline & & $\phi_{1}$ & $\phi_{2}$ & $\phi_{3}$ & $\phi_{4}$ & $\phi_{5}$ \\
${\text { Conf. } \#^{a}}$ & Rel. E & sp/ap & $\mathrm{H}_{2}-\mathrm{H}_{3}$ & $\mathrm{H}_{3}-\mathrm{H}_{4}$ & CH-COMe & CH-COOMe \\
\hline $1^{b}$ & 0.00 & ap & -175 & 59 & 5 & 174 \\
4 & 0.28 & ap & -47 & -175 & -133 & -124 \\
8 & 0.89 & ap & -52 & -173 & -128 & 43 \\
9 & 1.00 & ap & -171 & -71 & 5 & 177 \\
19 & 1.29 & sp & -179 & 58 & -168 & 150 \\
35 & 1.31 & $a p$ & 178 & 57 & -165 & 152 \\
59 & 1.33 & $a p$ & -159 & -176 & -1 & 162 \\
16 & 1.34 & $a p$ & 171 & 56 & -152 & -8 \\
7 & 1.56 & $s p$ & 171 & 47 & -153 & -7 \\
6 & 1.68 & $a p$ & -179 & 58 & 13 & 2 \\
46 & 1.90 & $s p$ & -175 & 59 & 5 & 174 \\
33 & 1.94 & $a p$ & 69 & -171 & -78 & 156 \\
99 & 3.74 & $s p$ & -178 & 62 & 10 & -8
\end{tabular}

${ }^{a}$ The conformation labels refer to the energy order obtained from MM conformational search. ${ }^{b}$ Conformation observed in the solid state.

the global minimum and they seem to disagree with the observed coupling constant values. To investigate this point, we calculated the NMR coupling constants $\mathrm{H} 2-\mathrm{H} 3$ and $\mathrm{H} 2-\mathrm{H} 4$ (corresponding to $\phi_{1}$ and $\phi_{2}$ ) at the GIAO-B3LYP/6-311++G(2d,p) level and including the Fermi contact term. ${ }^{18}$ The Boltzmann averaged values were $10.8 \mathrm{~Hz}$ and 6.1 for $\phi_{1}$ and $\phi_{2}$, in good agreement with the experimental values (see Table S1 in $\operatorname{ESI}_{\dagger} \dagger$ ). Once the three main descriptors are fixed, the optimized conformations differ by the relative disposition of the two carbonyl groups $\left(\phi_{4}\right.$ and $\left.\phi_{5}\right)$. It is worth to note that the conformation calculated as the most stable (\#1) is that observed in the X-ray structure (Fig. 3).

We also noted that only seven out of the eight available dispositions of the two carbonyl groups were present in the optimized geometries. For the sake of completeness, this last

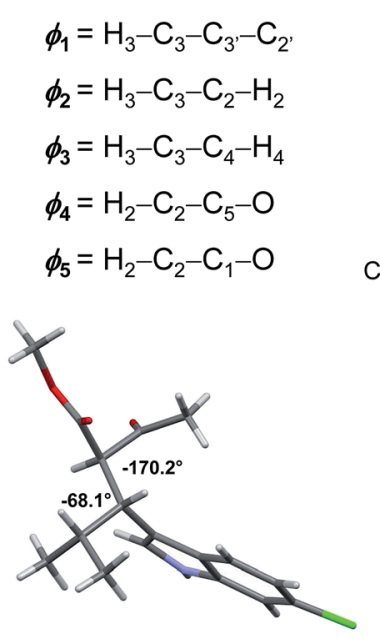

1a X-ray
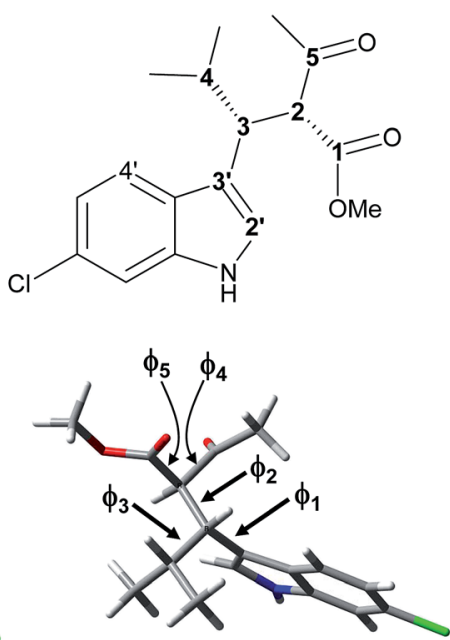

Conf. \#1
Fig. 3 The X-ray structure of 1 a and geometry of conformation \#1, with dihedrals definition as from Tables 1 and 2 . 
conformation (labelled as \#99) was manually built and optimized. Its energy was calculated to be $3.74 \mathrm{kcal} \mathrm{mol}^{-1}$ above the global minimum.

The same conformational analysis was performed for compound 1b. For this compound the MM conformational search found 107 conformations, which were reduced to 16 after optimization at the B3LYP/6-31G(d) level and elimination of the duplicates (Table 2 and Fig. S6 of ESI $\dagger$ ). As in 1a, the ap conformation is predominant (ten out of sixteen conformations), with only two $s p$ conformations enclosed among the first ten. Conformation \#21 corresponds to the experimental X-ray structure of $\mathbf{2 b}$ (actually its enantiomer), so in this case the calculated global minimum is not in agreement with the X-ray structure. However, $\mathbf{2 b}$ was crystallized from a polar solvent, whereas the calculations have been hitherto made in the gas phase.

To investigate the effect of various optimization parameters, the thirteen conformations of 1a were optimized using B3LYP and the larger $6-311++\mathrm{G}(2 \mathrm{~d}, \mathrm{p})$ basis set, and for each basis set the optimization was carried out both in the gas phase and in acetonitrile using the IEF-PCM formalism. ${ }^{19}$ Acetonitrile was used because it was solvent used to record the NMR and ECD spectra at ambient temperature (see below). Calculations yielded the four sets of data shown in Tables 3 and S2 of ESI. $\uparrow$ The relative energies are very different when the solvent is included in the calculations, whereas the effect of the different basis set is very small. ${ }^{20}$ When solvent is included, seven out of the eight most stable conformations have identical dihedral parameters, with the $\mathrm{H} 2-\mathrm{H} 3$ dihedral being anti and the $\mathrm{H} 3-\mathrm{H}_{\mathrm{i}-\mathrm{Pr}}$ gauche, in full agreement with experimental NMR data. Conformation \#1 is the most stable conformation in the gas-phase calculations, but the most stable conformation when the solvent is included is only the 35th in the MM search, with a relative energy of

Table 2 Summary of the relative energies (Rel. E) and geometric parameters of the sixteen conformations of $1 \mathrm{~b}$ after MM conformational search and optimization by DFT at the B3LYP/6-31G(d) level. Energies in $\mathrm{kcal} \mathrm{mol}^{-1}$

\begin{tabular}{lllllll}
\hline & & $\phi_{1}$ & $\phi_{2}$ & $\phi_{3}$ & $\phi_{4}$ & $\phi_{5}$ \\
Conf. $\#^{a}$ & Rel. E & $s p / a p$ & $\mathrm{H}_{2}-\mathrm{H}_{3}$ & $\mathrm{H}_{3}-\mathrm{H}_{4}$ & CH-COMe & CH-COOMe \\
\hline 37 & 0.00 & $a p$ & 44 & 178 & 122 & 151 \\
2 & 0.12 & $a p$ & 173 & -62 & -156 & -10 \\
14 & 0.46 & $a p$ & 49 & 175 & -42 & 141 \\
5 & 0.52 & $a p$ & -179 & -62 & 2 & 169 \\
$21^{b}$ & 1.09 & $a p$ & 176 & -63 & -160 & 169 \\
17 & 1.14 & $s p$ & 73 & 177 & -108 & 37 \\
3 & 1.24 & $a p$ & -66 & 170 & -150 & 70 \\
7 & 1.28 & $s p$ & -177 & -62 & -1 & 172 \\
23 & 1.33 & $a p$ & 156 & 175 & -150 & -1 \\
1 & 1.37 & $a p$ & -65 & 170 & -140 & -111 \\
15 & 1.48 & $s p$ & 79 & -177 & -107 & -146 \\
22 & 1.64 & $s p$ & 80 & -178 & -108 & -139 \\
9 & 1.66 & $a p$ & -178 & -61 & -1 & -14 \\
8 & 1.72 & $s p$ & 173 & -63 & -157 & -6 \\
20 & 1.95 & $a p$ & 179 & 62 & 153 & 4 \\
44 & 1.96 & $s p$ & 158 & 176 & -152 & -173 \\
& & & & & &
\end{tabular}

${ }^{a}$ The conformation label refers to the energy order obtained from MM conformational search. ${ }^{b}$ Conformation observed in the solid state.
Table 3 Relative energies of the best thirteen conformations of $1 \mathrm{a}$ calculated with B3LYP using two different basis sets, with or without the solvent (IEF-PCM). Relative energies in $\mathrm{kcal} \mathrm{mol}^{-1}$, as ZPE-corrected enthalpies

\begin{tabular}{lllll} 
Conf $\#^{a}$ & $6-31 G(d)$ & $6-311++G(2 d, p)$ & PCM-6-31G(d) & PCM-6-311++G(2d,p) \\
\hline 35 & 1.16 & 1.47 & $\mathbf{0 . 0 0}$ & $\mathbf{0 . 0 0}$ \\
$1^{b}$ & $\mathbf{0 . 0 0}$ & $\mathbf{0 . 0 0}$ & 0.51 & 0.30 \\
16 & 1.21 & 1.40 & 0.55 & 0.41 \\
6 & 1.68 & 1.70 & 1.59 & 1.07 \\
19 & 1.25 & 1.68 & 1.21 & 1.29 \\
59 & 1.22 & 1.65 & 1.85 & 1.45 \\
46 & 1.90 & 2.03 & 1.68 & 1.62 \\
7 & 1.56 & 1.49 & 1.72 & 1.74 \\
4 & 0.11 & 1.09 & 1.17 & 1.97 \\
9 & 1.04 & 1.42 & 1.95 & 2.09 \\
8 & 0.76 & 0.97 & 1.55 & 2.20 \\
99 & 3.75 & 3.90 & 2.84 & 2.52 \\
33 & 1.76 & 2.38 & 2.44 & 2.95
\end{tabular}

${ }^{a}$ The conformation label refers to the energy order obtained from MM conformational search. ${ }^{b}$ Conformation observed in the solid state.

$3.6 \mathrm{kcal} \mathrm{mol}^{-1} v s$. the global minimum, and $1.47 \mathrm{kcal} \mathrm{mol}^{-1} v s$. the gas-phase DFT calculations. This result confirms once more that conformational analysis has to take into account a broad energy range (at least $10 \mathrm{kcal} \mathrm{mol}^{-1}$ ) to guarantee that all the low energy conformations are included in the following DFT step.

Among the thermochemistry data obtained after frequency analysis, we choose to use the ZPE-corrected enthalpies, rather than the Gibbs free energies, to derive the relative energies. As a matter of fact, the use of uncorrected internal energies, ZPEcorrected enthalpies or Gibbs free energies did not modify the results to a great extent, except for a few conformations, in which the entropic correction yielded very different relative energies (e.g. conf. \#59 in Fig. 4, see also Fig. S5 in ESI†).

Frequency analysis revealed that about $10 \%$ of the values were below $200 \mathrm{~cm}^{-1}$, and about $25 \%$ were below $500 \mathrm{~cm}^{-1}$. Although some methods have been proposed to cushion this issue, ${ }^{21}$ they inevitably hampers the correct evaluation of the entropic factor in the thermochemistry corrections to the internal energies. In the conformational analysis realm, the ground state entropic factors between different conformations are expected to be very similar for different conformations, and the different entropic corrections obtained for the various conformations are mainly due to the contributions of the very low frequencies modes, all ascribable to internal conformational motions.

Based on the results of Table 3, we fixed the largest basis set and the inclusion of solvent, and we investigated the effects due to the functional, since B3LYP has been recently considered not fully appropriate for the relative energy evaluation. ${ }^{22}$ Among the

T This occurrence is not in contrast with the X-ray data because the crystals were grown from a low polarity solvent such as chloroform. Unfortunately, chloroform cannot be used for ECD because its absorbance limits the range of the ECD spectrum to $230 \mathrm{~nm}$. 


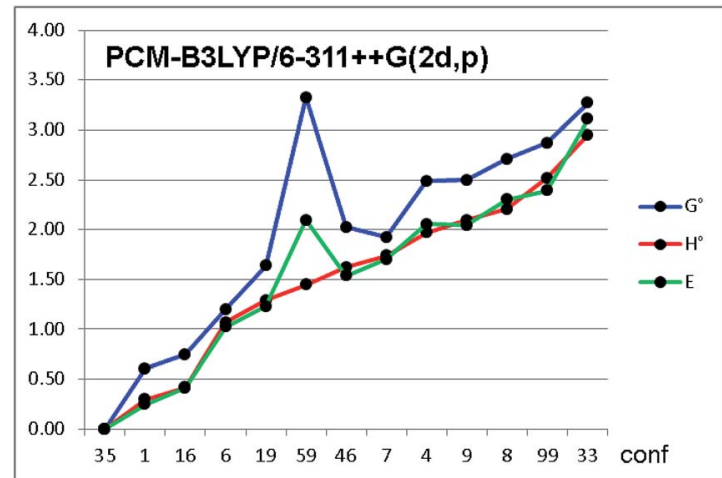

Fig. 4 Relative energies of the thirteen conformations of compound $1 \mathrm{a}$, optimized by PCM-B3LYP/6-311++G(2d,p). Green line = relative energy as uncorrected internal energy $(E)$; red line $=Z P E$-corrected enthalpy $\left(H^{\circ}\right)$; blue line $=$ ZPE-corrected Gibbs free energy $\left(G^{\circ}\right)$. Conformations on abscissa are arranged in increasing order of $H^{\circ}$. Energies in $\mathrm{kcal} \mathrm{mol}^{-1}$.

plethora of functionals developed so far, we selected the global hybrid M06-2 $\mathrm{x}^{23}$ and the range-separated hybrids M11 (ref. 24) and $\omega \mathrm{B} 97 \mathrm{X}-\mathrm{D} .^{25}$ The thirteen conformations of $\mathbf{1 a}$ and the sixteen of $\mathbf{1 b}$ were fully optimized again in acetonitrile (IEFPCM) using the three functionals and the $6-311++G(2 d, p)$ basis set (Table 4 and Fig. 5).

For each functional, the conformations of $\mathbf{1 a}$ within $1 \mathrm{kcal} \mathrm{mol}{ }^{-1}$ from the global minimum were optimized also using the SMD model ${ }^{26}$ for the solvent, without appreciable variations (see Table S3 of ESI $\dagger$ ). Three functionals (M06-2X, M11 and $\omega$ B97X-D) found the same global minimum for 1a (\#1). B3LYP and $\omega$ B97X-D performed similarly, whereas the two Minnesota functionals showed different trends, because conformations \#8, \#9 and \#4 were calculated as much more
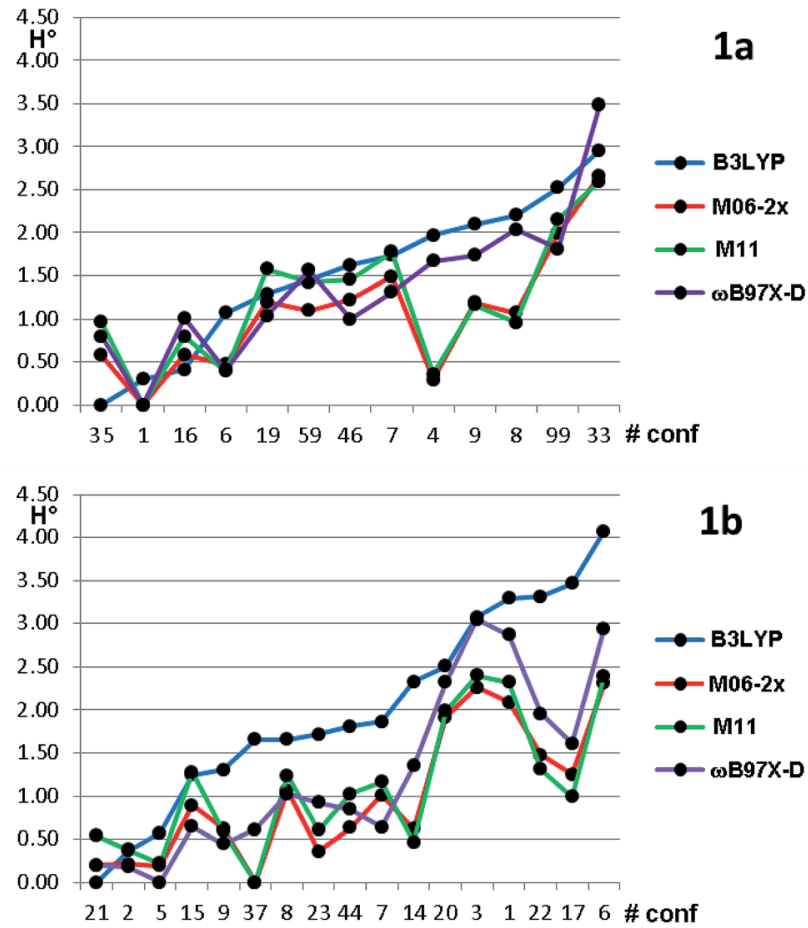

Fig. 5 Relative ZPE-corrected enthalpies for the thirteen conformations of $1 \mathrm{a}$ and the sixteen conformations of $1 \mathrm{~b}$. The abscissa reports the conformations numbers arranged in increasing energy order, based on B3LYP optimization. Energies in $\mathrm{kcal} \mathrm{mol}^{-1}$.

stable with respect to the other functionals. In all the cases the Boltzmann-averaged NMR coupling constants corresponding to $\phi_{2}$ and $\phi_{3}$ were in fair to good agreement with the experimental values (see Table S1 of ESI $\dagger$ ). Only three conformations were found by B3LYP and $\omega$ B97X-D within the $0-1 \mathrm{kcal} \mathrm{mol}^{-1}$ range,

Table 4 Relative ZPE-corrected enthalpies for the conformations of $1 \mathrm{a}$ and $1 \mathrm{~b}$, calculated in acetonitrile with various functionals and the 6 $311++G(2 d, p)$ basis set. Relative energies are in $\mathrm{kcal} \mathrm{mol}^{-1}$. Bold numbers indicate the conformations within the $1 \mathrm{kcal}^{\mathrm{mol}}{ }^{-1}$ limit vs. the global minimum (bold and underlined)

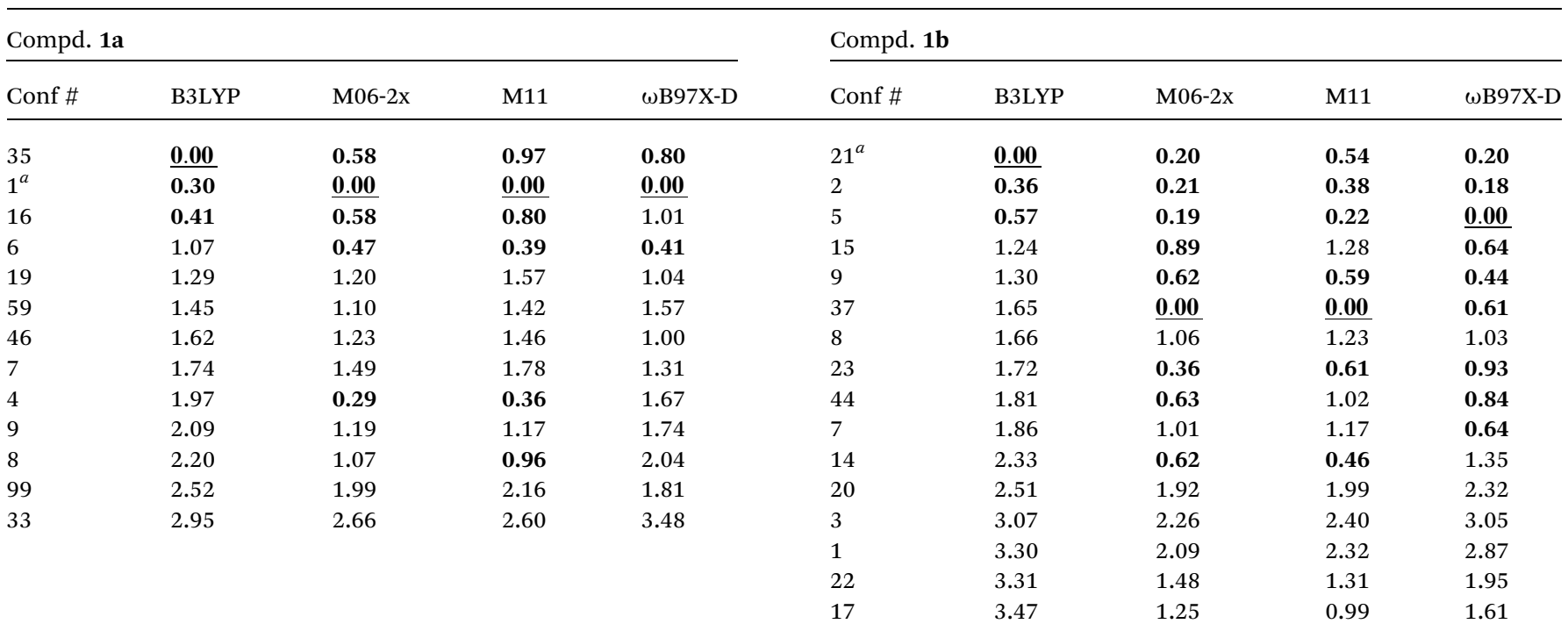

\footnotetext{
${ }^{a}$ Conformation observed in the solid state.
} 
whereas M06-2x and M11 found five and six conformations in the same range, respectively. It appears that B3LYP and $\omega$ B97X$\mathrm{D}$ results are in better agreement with the experimental data, while M06-2x and M11 slightly overestimate the stability of two conformations, whose population is experimentally small on the basis of NMR coupling constant analysis. The same computational process applied to compound $\mathbf{1 b}$ gave even more complex results. Three different conformations were calculated as the global minima from B3LYP, $\omega$ B97X-D, and by the two Minnesota functionals. B3LYP found only three conformations within $1.0 \mathrm{kcal} \mathrm{mol}^{-1}$ from the global minimum; $\omega$ B97X-D found nine conformations within the same energy range. The relative energy of conformation \#21 (that found in the solid state) is always very low, but it corresponds to the global minimum only in the B3LYP optimization. It should be also noted that the conformation found as global minimum by both the Minnesota functionals is $\# 37$, whose energy is $1.65 \mathrm{kcal} \mathrm{mol}^{-1}$ in the B3LYP calculations. From the structural point of view, conformation \#37 has the isopropyl $\mathrm{CH}$ in antidisposition with $\mathrm{H}-3$, whereas the small experimental NMR coupling constant value suggests that the most populated conformations have a gauche relationship.

\section{Absolute configuration}

In the past few years, the computational methods based on DFT and TD-DFT calculations for the simulation of chiro-optical spectra have known a widespread use. It has often underlined that the simulations are heavily influenced by the geometries employed in the calculation. ${ }^{27,28}$ Compounds $\mathbf{1 a}$ and $\mathbf{1 b}$ have a single strong UV-chromophoric group (i.e. the indole ring), and the two stereogenic carbons do not bear any additional UV moiety that could interact with the indole to produce exciton couplings. ${ }^{29}$ As shown by calculations above, the conformational flexibility of these compounds is reflected by the existence of many low-energy conformations. The large conformational freedom and the absence of multiple chromophores make the simulation of chiro-optical spectra particularly challenging. The UV and ECD spectra of $\mathbf{1 a}$ and $\mathbf{1 b}$ were obtained in acetonitrile as the average of 16 spectra taken in the 185-400 nm region (Fig. 6). The UV spectra are dominated by the absorption bands of the indole ${ }^{30}$ and, as conceivable, the ECD spectra are rather weak. Compound 1a shows a weak and structured positive band between 295 and $305 \mathrm{~nm}$, two negative bands at 235 and $195 \mathrm{~nm}$, and a broad positive band in the 230$200 \mathrm{~nm}$ region. Compound $\mathbf{1 b}$ has two broad negative bands in the $290-240 \mathrm{~nm}$ region, and positive bands in the high-energy region (230 and $205 \mathrm{~nm}$ ).

To simulate the experimental ECD spectrum, the spectra of all conformations have to be simulated and then mixed using the Boltzmann distribution. Therefore, two main factors influence the shape of the final simulated spectrum: (1) the combination of functional and basis set used for the calculation of the ECD spectrum by TD-DFT; (2) the combination used for the geometry optimization. The latter step also affords the conformational ratio to be applied in the Boltzmann averaged spectrum. TD-DFT calculations were performed in two steps. Firstly,

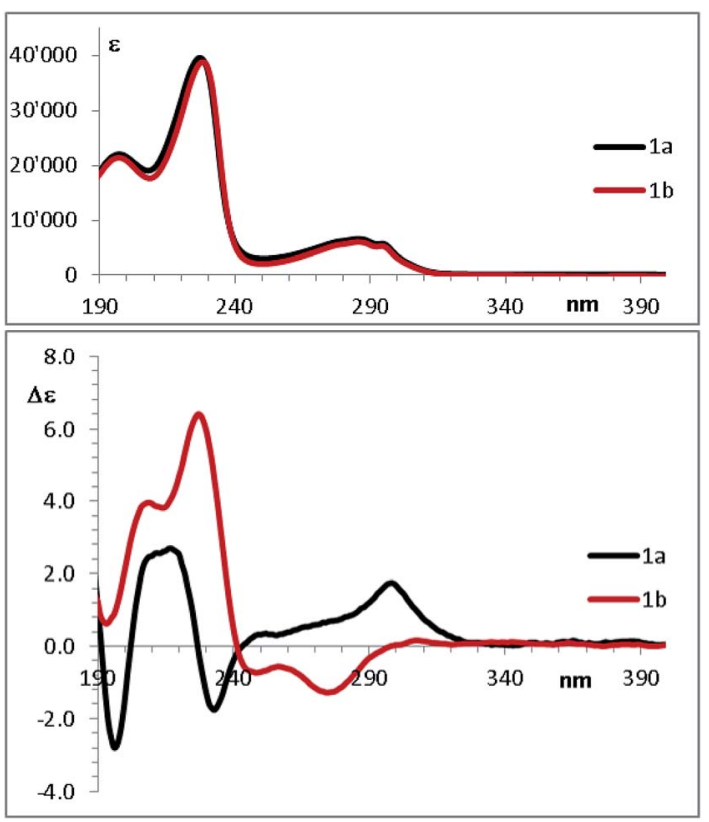

Fig. 6 UV (top) and ECD spectra (bottom) of $1 \mathrm{a}$ and $1 \mathrm{~b}$ in acetonitrile.

we simulated the ECD spectrum of $1 \mathrm{a}(2 R, 3 R$ absolute configuration) at the CAM-B3LYP/6-311++G(2d,p) level using the geometries obtained with the B3LYP functional combined with two different basis set [6-31G(d) and 6-311++G(2d,p)], both the in the gas-phase and with the solvent. For each conformation, the first 50 excited states were calculated, and the spectra were obtained using a $0.25 \mathrm{eV}$ linewidth at half height. As shown in Fig. 7, the differences among the four ECD spectra calculated for the same conformation are extremely small. For some conformations the simulations in the gas phase and in acetonitrile, obtained with the same basis set, are even superimposable (see Fig. S8 of ESI $\dagger$ ). This result suggests that the optimized geometries are very similar, and in many cases almost identical.

On the other hand, the calculated spectra are very different among the thirteen conformations (an example of superimposition of the spectra is shown in Fig. S7 of the ESI $\dagger$ ), so the conformational ratio employed in the Boltzmann-averaged simulation of the experimental ECD spectrum will play a key role to correctly simulate the experimental spectra. This situation is due to the presence of a single UV chromophoric group, which makes the spectra very weak and strongly dependent on the whole molecular geometry. For example, conformation \#1 and \#6 are both ap conformations differentiated by the rotation of COOMe moiety, and the pairs \#6/\#16 and \#1/\#35 have different conformations due to the rotation of the COMe group.

As the second step, the PCM-B3LYP/6-311++G(2d,p) optimized geometries were used for the TD-DFT calculations using CAM-B3LYP ${ }^{31}$ with four different basis sets [6-311++G(2d,p), 6$311 \mathrm{G}(\mathrm{d}, \mathrm{p}), 6-31+\mathrm{G}(\mathrm{d}, \mathrm{p})$ and $6-31 \mathrm{G}(\mathrm{d})]$. The results (Fig. S9 of $\left.\mathrm{ESI}^{\dagger}\right)$ show that the four simulations are always very similar in the low-energy region, but quite different in the high-energy region where charge transfer (CT) and Rydberg transitions take place. Careful inspection revealed indeed that the pair of 

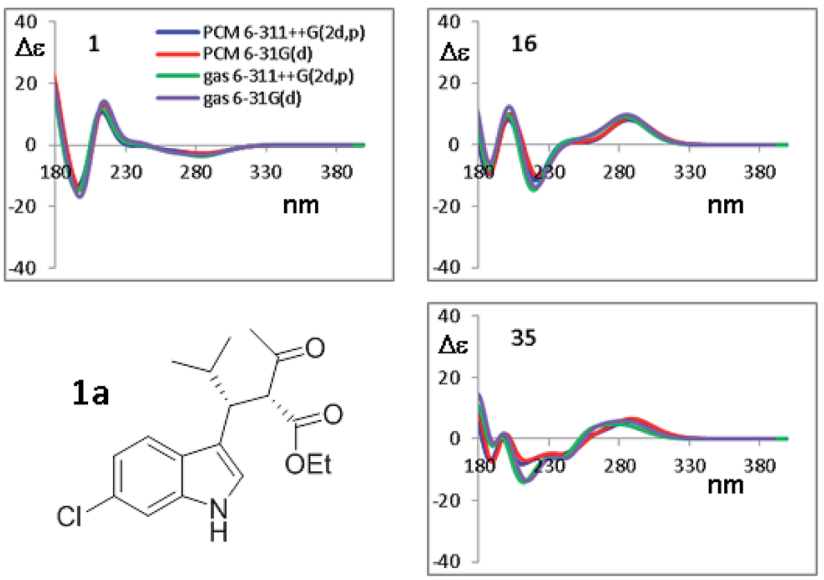

Fig. 7 Selected TD-DFT simulations obtained at the CAM-B3LYP/6$311++G(2 d, p)$ level using the four geometries optimized by B3LYP, using the $6-31 G(d)$ and $6-311++G(2 d, p)$ basis sets, in both the gas phase and including the solvent acetonitrile. Only the spectra for three most stable conformations from Table 3 are shown. All the simulations are reported in Fig. S8 of ESI. $\dagger$

basis sets including diffuse functions yield very similar spectra, as does the pair without diffuse functions.

The ECD spectra of the thirteen conformations of 1a were then calculated using the four sets of optimized geometries obtained by PCM-B3LYP, PCM-M06-2x, PCM-M11 and PCM$\omega \mathrm{B} 97 \mathrm{X}-\mathrm{D}$ and the same $6-311++\mathrm{G}(2 \mathrm{~d}, \mathrm{p})$ basis set. Based on previous experience, ${ }^{32}$ TD-DFT calculations were performed with BH\&HLYP, ${ }^{33}$ M06-2x, $\omega$ B97X-D and CAM-B3LYP. All the ECD spectra were calculated using the 6-311++G(2d,p) basis set, eventually yielding a $4 \times 4$ data matrix for each conformation. With these data sets in hand, first we checked the effect of the different optimized geometries on the simulated spectra, calculated with the same TD-DFT functional.

The results shown in Fig. 8 for CAM-B3LYP suggest that the input geometries optimized with four different functionals yield very similar ECD spectra, with tiny differences mainly located in the high-energy region of the spectrum (e.g. conformations \#7 and \#35; the remaining spectra of $\mathbf{1 a}$ and those of $\mathbf{1 b}(2 S, 3 R \mathrm{AC})$ are reported in Fig. S10-S17 of ESI $\dagger$ ). Both the optimization functionals, and the optimization basis set as well (see Fig. 7), have a very little influence on the final result. This also suggests that it is not necessary to recalculate the ECD spectra using geometries coming from additional optimizations, as this will not lead to more accurate results.

The orthogonal test compares the results when different TDDFT functionals are used with the same input geometry (Fig. 9 shows the case of B3LYP optimization of compound 1a, the remaining simulations are reported in Fig. S18-S21 of ESI†). In some conformations, such as \#1, the four simulations are almost superimposable, whereas in others cases $\# 8$, \#9, \#16, $\# 35$ ) the low energy Cotton effect is calculated at very different wavelength. In some cases (\#6 and \#19) the shape is similar but the relative intensities of the Cotton effects are different. The same situation occurs for compound 1b (Fig. S22-S24 in ESI $\dagger$ ). The largest effect is determined by the type of functional used in TD-DFT calculations, due to the peculiar features of each single

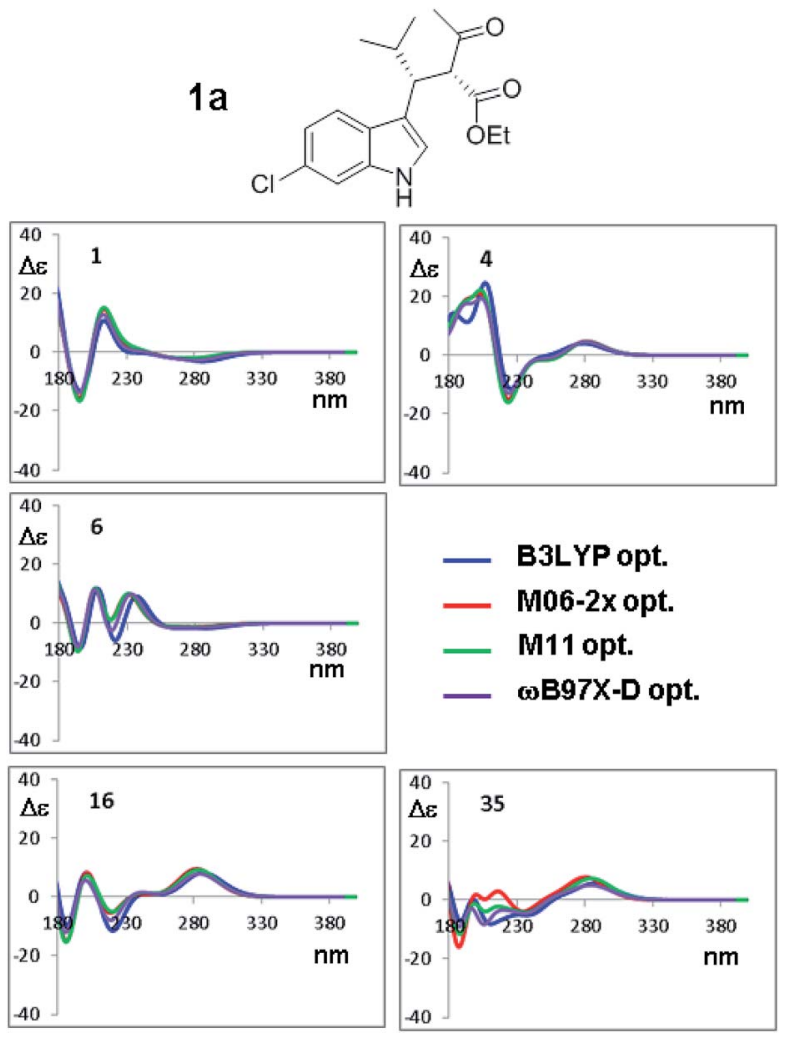

Fig. 8 Selected ECD simulations for the conformations of 1a. The number in each quadrant is the conformation label, the four colored lines are the ECD spectra obtained with TD-DFT using CAM-B3LYP/6$311++G(2 d, p)$ and the four geometry sets obtained with the four different functionals, including the solvent (PCM) and with the same 6$311++\mathrm{G}(2 \mathrm{~d}, \mathrm{p})$ basis set. The simulations for all the conformations are reported in ESI. $\dagger$

functional. As pointed out many times, ${ }^{34}$ the use of multiple methods is a convenient and recommended way to achieve data redundancy, and to enhance calculations reliability.

The last factor for the successful simulation of the experimental ECD spectra is the conformational ratio employed when mixing the spectra of each conformation. ${ }^{35}$ The ECD simulations of the experimental spectra were obtained using the conformational ratios derived from Table 4 by Boltzmann weighted average at $+25{ }^{\circ} \mathrm{C}$ (Fig. 10 of ESI $\dagger$ ).

The comparison of the simulated UV spectra with the experimental ones showed a very good agreement in all the simulations (Fig. S26-S29 of ESI $\dagger$ ). The goodness of the fit between the simulated and the experimental ECD spectra was evaluated with SpecDis software, ${ }^{5,6 a, 36}$ using the difference between the two similarity factors calculated for the correct enantiomer and that for the wrong one $\left(\Delta S_{\mathrm{f}}\right) . \|$ Fig. 10 reports the best and the worse simulations obtained for compounds $\mathbf{1 a}$

\| This parameter has the same meaning of that defined as $\Delta$ in the SpecDis manual, p. 15. 


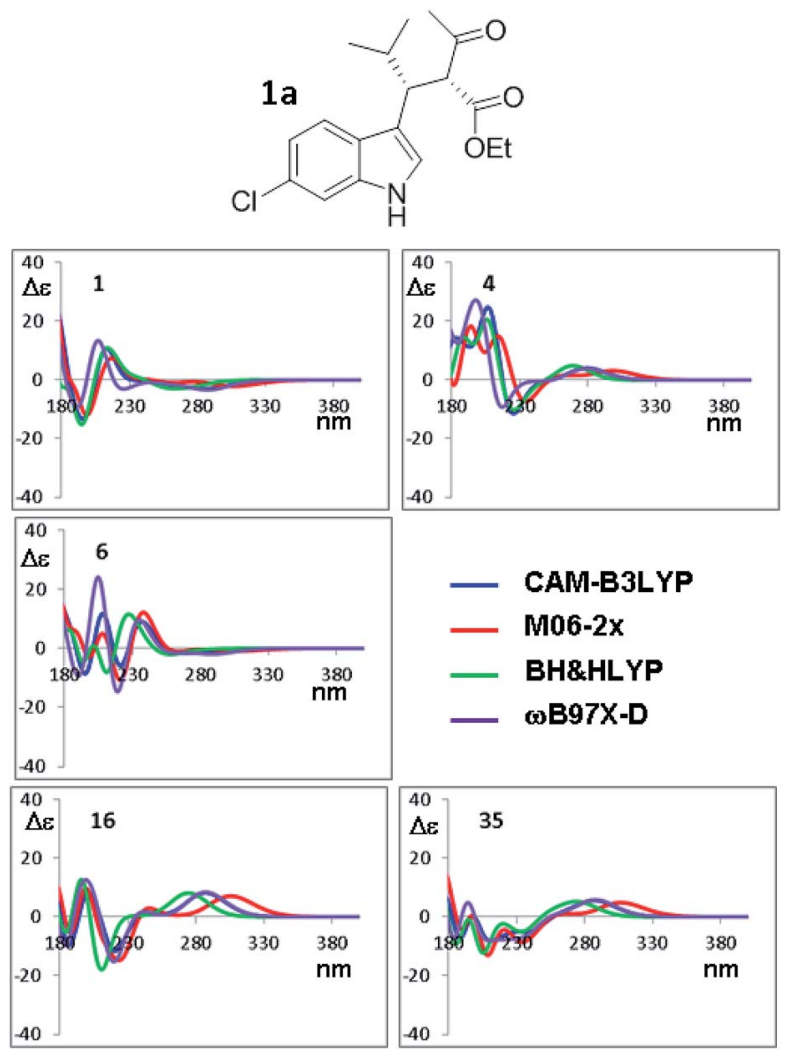

Fig. 9 Selected ECD simulations for the conformations of 1a. The number in each quadrant indicates the conformation label, the four colored lines are the ECD spectra obtained with the four different functionals using the geometries obtained with PCM-B3LYP/6$311++G(2 d, p)$. The simulations for all the conformations are reported in ESI. $\uparrow$

and $\mathbf{1 b}$, whereas Fig. 11 reports the $\Delta S_{\mathrm{f}}$ values for all the sixteen simulations (all the spectra comparison and the raw data provided by SpecDis are reported in Fig. S30 and S31 of ESI $†$ ).**

As a whole, the TD-DFT simulations obtained by BH\&HLYP and M06-2x are always the worse (as mean value of $\Delta S_{\mathrm{f}}$ ), regardless of the optimization method used to evaluate the conformational ratio. In two cases of $\mathbf{1 a}$ and in three of $\mathbf{1 b}$, the simulations for the opposite enantiomer had a better $S_{\mathrm{f}}$ score (right section of Fig. 10). On the other side, the TD-DFT simulations obtained by the two range-separated functionals CAMB3LYP and $\omega$ B97X-D are in a much better agreement with the experimental spectra. ${ }^{37}$ In these two series the $\Delta S_{\mathrm{f}}$ is always quite good $\left(\Delta S_{\mathrm{f}}>0.58\right.$ for both 1a and $\left.\mathbf{1 b}\right)$ and the difference among the four available conformational ratios is small, being the ratio suggested by $\omega$ B97X-D optimization the worse. The influence of the different conformational ratio is particularly evident in the simulation of the broad positive band centered at $300 \mathrm{~nm}$, that is calculated to be opposite in sign on changing the conformation. In this region, where the TD-DFT

** The simulations of the UV spectra required a red-shift $(\Delta \lambda)$ of the calculated spectra between 20 and $25 \mathrm{~nm}$, whereas the ECD spectra of $1 \mathbf{a}$ and $\mathbf{1 b}$ were better simulated by a smaller correction, with a significant improvement of the similarity factor.
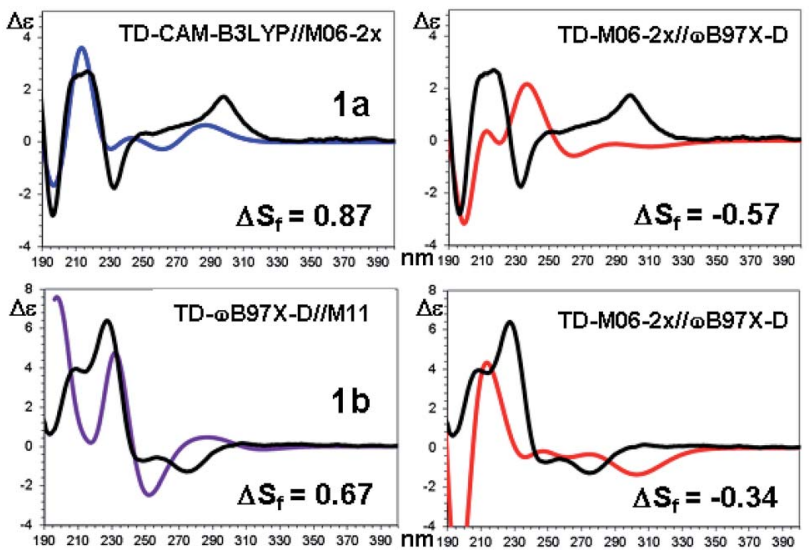

Fig. 10 TD-DFT simulations (colored traces) of the experimental ECD spectrum (black trace) of $1 \mathrm{a}$ (top) and $1 \mathrm{~b}$ (bottom). For each compound the best and the worse simulation are reported (see text for the definition of $\Delta S_{f}$ and $E S I \dagger$ for the full set of simulations with the related red shifts and scaling factors).

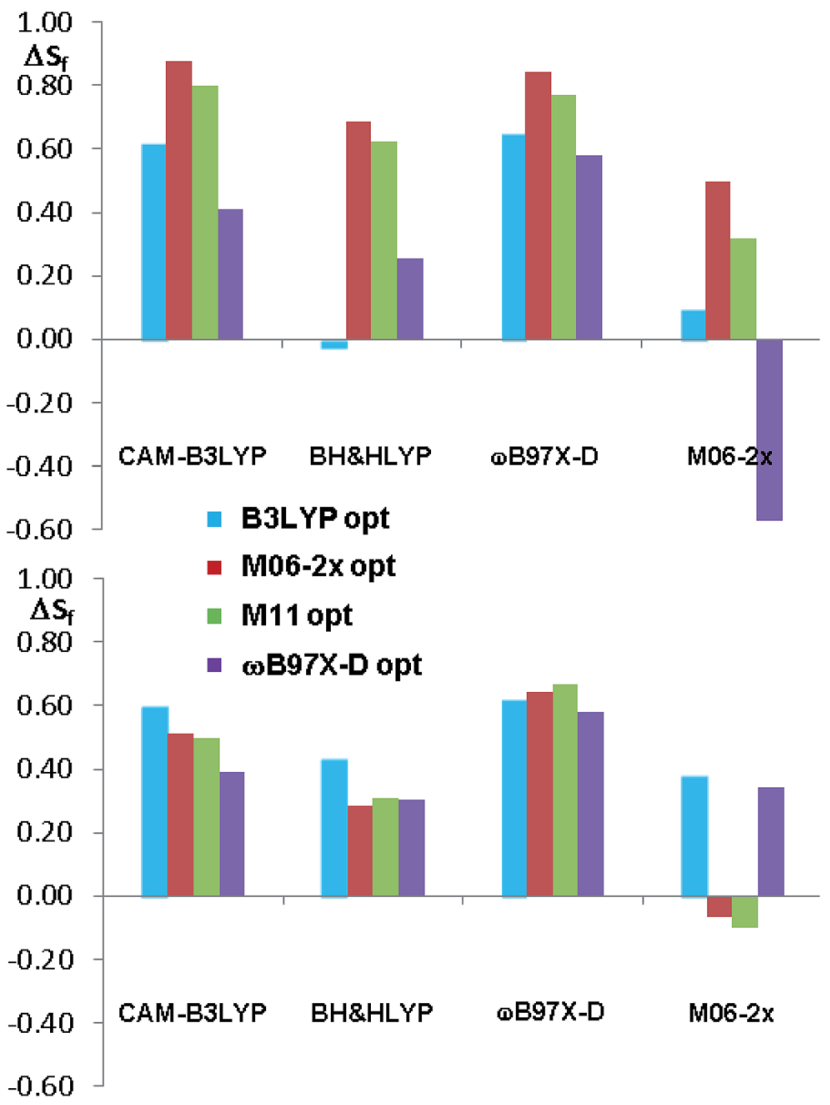

Fig. 11 Summary of the $\Delta S_{f}$ values for the sixteen ECD simulations of compounds $1 \mathrm{a}$ and $1 \mathrm{~b}$. The different colors indicate the different geometry optimization methods.

calculations should be more reliable, the conformational ratio suggested by B3LYP provides the best results. On the contrary, the B3LYP conformational ratio does not simulate well the highenergy region. 


\section{Conclusions}

The assignment of the AC of very flexible organic molecules by means of chiro-optical spectra supported by quantummechanical simulation is a challenging task because of the presence of many populated conformations. The results obtained in this study show that different functionals yield very similar geometries, that provide very similar TD-DFT simulations.

On the other hand, the relative energies derived from the optimization step are of primary importance to determine the final result, and the inclusion of solvent in the calculations plays a very large effect on the conformational ratio. B3LYP and M06-2x functionals provided the best results in terms of the conformational ratio. In the TD-DFT simulations the two rangeseparated CAM-B3LYP and $\omega$ B97X-D functionals provided the best results. This study confirms once more the importance of using many combinations of functionals and basis set for TDDFT, and more than a single functional for the evaluation of the conformational ratio.

\section{Experimental section}

\section{NMR spectra}

NMR spectra were recorded using a spectrometer operating at $400 \mathrm{MHz}$ for ${ }^{1} \mathrm{H}$ and 100.6 for ${ }^{13} \mathrm{C}$. Chemical shifts are reported in ppm relative to TMS as the internal standard. The assignment of the ${ }^{13} \mathrm{C}$ signals was obtained by means of DEPT, gsHSQC and gs-HMBC spectra. The ${ }^{13} \mathrm{C}$ spectra were acquired under proton decoupling conditions with $5.5 \mu \mathrm{s}$ ( $60^{\circ}$ tip angle) pulse width, $1 \mathrm{~s}$ acquisition time and $3 \mathrm{~s}$ delay time. NOE spectra were obtained at $600 \mathrm{MHz}$ using the DPFGSE sequence and a $50 \mathrm{~Hz}$ wide selective pulse with a R-SNOB shape. The low temperature ${ }^{1} \mathrm{H}$ NMR spectra were obtained at $600 \mathrm{MHz}$ by using a flow of dry nitrogen through an heat exchanger immersed in liquid nitrogen and connected to the NMR probe by a vacuum-insulated transfer line. The ${ }^{1} \mathrm{H}$ spectra were acquired using a $5 \mathrm{~mm}$ direct probe with a $9000 \mathrm{~Hz}$ spectral width, $2.0 \mu \mathrm{s}\left(20^{\circ}\right.$ tip angle) pulse width, $3 \mathrm{~s}$ acquisition time and $1 \mathrm{~s}$ delay time. A shifted sine bell weighting function equal to the acquisition time (i.e., $3 \mathrm{~s}$ ) was applied before the Fourier transformation. Temperature calibrations were performed before the experiments, using a $\mathrm{Cu} / \mathrm{Ni}$ thermocouple placed in an NMR tube filled with isopentane.

\section{UV and ECD spectra}

UV and ECD spectra were recorded at $+25^{\circ} \mathrm{C}$ in far-UV HPLCgrade acetonitrile solutions. The concentrations of the samples were calibrated by dilution of a mother solution $(1 \times$ $10^{-3} \mathrm{M}$ ) to obtain a maximum absorbance of about 1.0 in the UV spectrum using a $0.2 \mathrm{~cm}$ path length. Final concentrations were $9.9 \times 10^{-5} \mathrm{M}$ for $\mathbf{1 a}$ and $9.3 \times 10^{-5} \mathrm{M}$ for $\mathbf{1 b}$. The spectra were recorded on a Jasco J-810 spectropolarimeter in the $185-400 \mathrm{~nm}$ range at $50 \mathrm{~nm} \min ^{-1}$ as the average of 16 spectra. $\Delta \varepsilon$ is expressed as $\mathrm{L} \mathrm{mol}^{-1} \mathrm{~cm}^{-1}$.

\section{DFT calculations}

Ground state optimizations were obtained by DFT with the Gaussian 16 rev A.03 series of programs, ${ }^{17}$ using standard convergence parameters. The analysis of the vibrational frequencies for the optimized structures showed the absence of imaginary frequencies. The ECD spectra were calculated with TD-DFT using BH\&HLYP, M06-2x, $\omega$ B97XD, CAMB3LYP and the 6-311++G(2d,p) basis set. 50 discrete transitions were calculated for each conformation (lowest calculated wavelength about $160 \mathrm{~nm})$. The ECD spectra were generated by convolution of Gaussian shaped lines ( $0.25 \mathrm{eV}$ line width).$^{38}$ The simulated spectra resulting from the Boltzmann averaged sum of the conformations were vertically scaled and red-shifted using SpecDis rev. 1.71 (ref. 36) to get the direct comparison with the experimental spectra.

\section{Materials}

Compound $\mathbf{1 a}+\mathbf{2 a}$ and $\mathbf{1 b}+\mathbf{2 b}$ were prepared following a reported procedure. ${ }^{7}$

1a + 2a. ${ }^{1} \mathrm{H}-\mathrm{NMR}\left(400 \mathrm{MHz}, \mathrm{CD}_{3} \mathrm{CN}\right) .0 .78(\mathrm{~d}, 3 \mathrm{H}, J=6.9 \mathrm{~Hz})$, $0.84(\mathrm{~d}, 3 \mathrm{H}, J=6.9 \mathrm{~Hz}), 1.93(\mathrm{~s}, 3 \mathrm{H}), 2.01(\mathrm{~m}, 1 \mathrm{H}), 3.75(\mathrm{~s}, 3 \mathrm{H})$, $3.80(\mathrm{dd}, 1 \mathrm{H}, J=11.9,3.9 \mathrm{~Hz}), 4.19$ (d, $1 \mathrm{H}, J=11.9 \mathrm{~Hz}), 7.07$ (dd, $1 \mathrm{H}, J=8.5,1.9 \mathrm{~Hz}$ ), 7.10 (d, $1 \mathrm{H}, J=2.5 \mathrm{~Hz}), 7.43$ (d, 1H, $J=1.9$ $\mathrm{Hz}), 7.63(\mathrm{~d}, 1 \mathrm{H}, J=8.5 \mathrm{~Hz}), 9.34(\mathrm{bs}, 1 \mathrm{H}) .{ }^{13} \mathrm{C}-\mathrm{NMR}(100.6 \mathrm{MHz}$, $\left.\mathrm{CD}_{3} \mathrm{CN}\right)$. 16.9 $\left(\mathrm{CH}_{3}\right), 21.6\left(\mathrm{CH}_{3}\right), 28.6(\mathrm{CH}), 30.5\left(\mathrm{CH}_{3}\right), 41.7(\mathrm{CH})$, $52.4\left(\mathrm{CH}_{3}\right), 64.0\left(\mathrm{CH}_{3}\right), 111.3(\mathrm{CH}), 112.4(\mathrm{C}), 119.7(\mathrm{CH}), 120.7$ (CH), 124.9 (CH), 127.1 (C), 127.5 (C), 136.4 (C), 169.7 (COOMe), 202.4 (COMe). HRMS (ESI-Orbitrap), calcd. for $\left[\mathrm{C}_{17} \mathrm{H}_{21} \mathrm{NO}_{3} \mathrm{Cl}\right]^{+}$ 322.12045; found 322.1209. Crystals suitable for X-ray diffraction analysis were obtained from a chloroform solution by evaporation (about $24 \mathrm{~h}$ ).

1b + 2b. ${ }^{1} \mathrm{H}-\mathrm{NMR}\left(400 \mathrm{MHz}, \mathrm{CD}_{3} \mathrm{CN}\right) .0 .80(\mathrm{~d}, 3 \mathrm{H}, J=6.7 \mathrm{~Hz})$, $0.81(\mathrm{~d}, 3 \mathrm{H}, J=6.7 \mathrm{~Hz}), 1.93(\mathrm{~m}, 1 \mathrm{H}), 2.27$ (s, 3H), $3.35(\mathrm{~s}, 3 \mathrm{H})$, $3.79(\mathrm{dd}, 1 \mathrm{H}, J=11.3,4.7 \mathrm{~Hz}), 4.19$ (d, $1 \mathrm{H}, J=11.3 \mathrm{~Hz}), 7.06$ (dd, $1 \mathrm{H}, J=8.6,2.0 \mathrm{~Hz}), 7.13(\mathrm{~d}, 1 \mathrm{H}, J=2.5 \mathrm{~Hz}), 7.42(\mathrm{~d}, 1 \mathrm{H}, J=2.0$ $\mathrm{Hz}), 7.63(\mathrm{~d}, 1 \mathrm{H}, J=8.6 \mathrm{~Hz}), 9.30(\mathrm{bs}, 1 \mathrm{H}) .{ }^{13} \mathrm{C}-\mathrm{NMR}(100.6 \mathrm{MHz}$, $\left.\mathrm{CD}_{3} \mathrm{CN}\right)$. 17.2 $\left(\mathrm{CH}_{3}\right), 21.7\left(\mathrm{CH}_{3}\right), 28.7(\mathrm{CH}), 30.4\left(\mathrm{CH}_{3}\right), 41.4(\mathrm{CH})$, $51.8\left(\mathrm{CH}_{3}\right), 64.2\left(\mathrm{CH}_{3}\right), 111.2(\mathrm{CH}), 113.1(\mathrm{C}), 119.5(\mathrm{CH}), 120.7$ (CH), 126.9 (CH), 127.8 (C), 127.8 (C), 136.4 (C), 169.2 (COOMe), 203.2 (COMe). HRMS (ESI-Orbitrap), calcd. for $\left[\mathrm{C}_{17} \mathrm{H}_{21} \mathrm{NO}_{3} \mathrm{Cl}\right]^{+}$ 322.12045; found 322.1201. Crystals suitable for X-ray diffraction analysis were obtained from an acetonitrile solution by slow evaporation (about 10 days).

\section{Conflicts of interest}

There are no conflicts to declare.

\section{Acknowledgements}

Financial contribution was received by A. M., E. M. and M. M. from the University of Bologna (RFO funds 2016 and 2017). Financial contribution was received by C. V. and R. F. from the University of Rome La Sapienza (DR n 2936/17). ALCHEMY Fine Chemicals \& Research (Bologna, www.alchemy.it) is gratefully acknowledged for a generous gift of chemicals. 


\section{Notes and references}

1 J. M. Bijvoet, A. F. Peerdeman and A. J. van Bommel, Nature, 1951, 168, 271.

2 H. D. Flack and G. Bernardinelli, Chirality, 2008, 20, 681.

3 (a) E. C. Escudero-Adán, J. Benet-Buchholz and P. Ballester, Acta Crystallogr., Sect. B: Struct. Sci., Cryst. Eng. Mater., 2014, 70, 660; (b) R. W. W. Hooft, L. H. Straver and A. L. Spek, J. Appl. Crystallogr., 2008, 41, 96.

4 For a recent review see: S. Superchi, P. Scafato, M. Górecki and G. Pescitelli, Curr. Med. Chem., 2018, 25, 287; see also: M. Srebro-Hooper and J. Autschbach, Annu. Rev. Phys. Chem., 2017, 68, 399.

5 (a) J. Autschbach, T. Ziegler, S. J. A. van Gisbergen and E. J. Baerends, J. Chem. Phys., 2002, 116, 6930; (b) S. Grimme, in Reviews in computational chemistry, ed. K. B. Lipkowitz, R. Larter, and T. R. Cundari, John Wiley \& Sons, Hoboken, 2004, vol. 20, p 153; (c) T. D. Crawford, Theor. Chem. Acc., 2006, 115, 227; (d) G. Bringmann, T. Bruhn, K. Maksimenka and Y. Hemberger, Eur. J. Org. Chem., 2009, 2717; (e) G. Pescitelli and T. Bruhn, Chirality, 2016, 28, 466.

6 (a) T. Bruhn, A. Schaumloffel, Y. Hemberger and G. Bringmann, Chirality, 2013, 25, 243; (b) Compute VOA ${ }^{T M}$, Biotools Inc.

7 (a) A. D. Laurent and D. Jacquemin, Int. J. Quantum Chem., 2013, 113, 2019; (b) D. Jacquemin, V. Wathelet, E. A. Perpète and C. Adamo, J. Chem. Theory Comput., 2009, $5,2420$.

8 L. Goerigk, J. Moellmann and S. Grimme, Phys. Chem. Chem. Phys., 2009, 11, 4611.

9 M. Rudolph and J. Autschbach, J. Phys. Chem. A, 2011, 115, 14677.

10 A. Renzetti, E. Dardennes, A. Fontana, P. De Maria, J. Sapi and S. Gérard, J. Org. Chem., 2008, 73, 6824.

11 A. Renzetti, A. Di Crescenzo, F. Nie, A. D. Bond, S. Gérard, J. Sapi, A. Fontana and C. Villani, Chirality, 2015, 27, 779.

12 S. Parsons, H. D. Flack and T. Wagner, Acta Crystallogr., Sect. B: Struct. Sci., Cryst. Eng. Mater., 2013, 69, 249.

13 M. J. Minch, Concepts Magn. Reson., 1994, 6, 41.

14 D. Casarini, L. Lunazzi and A. Mazzanti, J. Org. Chem., 1997, 62, 3315.

15 (a) W. Klyne and V. Prelog, Experientia, 1960, 16, 521-523; (b) B. Testa, Principles of Organic Stereochemistry, Studies in Organic Chemistry, Marcel Dekker, New York, 1979, vol. 6, p. 87.

16 (a) C. Lee, W. Yang and R. G. Parr, Phys. Rev. B: Condens. Matter Mater. Phys., 1988, 37, 785; (b) A. D. Becke, J. Chem. Phys., 1993, 98, 5648; (c) P. J. Stephens, F. J. Devlin, C. F Chabalowski and J. M. Frisch, J. Phys. Chem., 1994, 98, 11623.

17 M. J. Frisch, G. W. Trucks, H. B. Schlegel, G. E. Scuseria, M. A. Robb, J. R. Cheeseman, G. Scalmani, V. Barone, G. A. Petersson, H. Nakatsuji, X. Li, M. Caricato, A. V. Marenich, J. Bloino, B. G. Janesko, R. Gomperts, B. Mennucci, H. P. Hratchian, J. V. Ortiz, A. F. Izmaylov,
J. L. Sonnenberg, D. Williams-Young, F. Ding, F. Lipparini, F. Egidi, J. Goings, B. Peng, A. Petrone, T. Henderson, D. Ranasinghe, V. G. Zakrzewski, J. Gao, N. Rega, G. Zheng, W. Liang, M. Hada, M. Ehara, K. Toyota, R. Fukuda, J. Hasegawa, M. Ishida, T. Nakajima, Y. Honda, O. Kitao, H. Nakai, T. Vreven, K. Throssell, J. A. Montgomery Jr, J. E. Peralta, F. Ogliaro, M. J. Bearpark, J. J. Heyd, E. N. Brothers, K. N. Kudin, V. N. Staroverov, T. A. Keith, R. Kobayashi, J. Normand, K. Raghavachari, A. P. Rendell, J. C. Burant, S. S. Iyengar, J. Tomasi, M. Cossi, J. M. Millam, M. Klene, C. Adamo, R. Cammi, J. W. Ochterski, R. L. Martin, K. Morokuma, O. Farkas, J. B. Foresman, and D. J. Fox,Gaussian 16, Revision A.03, Gaussian, Inc., Wallingford CT, 2016.

18 W. Deng, J. R. Cheeseman and M. J. Frisch, J. Chem. Theory Comput., 2006, 2, 1028.

19 J. Tomasi, B. Mennucci and R. Cammi, Chem. Rev., 2005, 105, 2999.

20 A. Debbab, A. H Aly, R. Edrada-Ebel, V. Wray, A. Pretsch, G. Pescitelli, T. Kurtan and P. Proksch, Eur. J. Org. Chem., 2012, 1351.

21 (a) R. F. Ribeiro, A. V. Marenich, C. J. Cramer and D. G. Truhlar, J. Phys. Chem. B, 2011, 115, 14556; (b) S. Grimme, Chem. - Eur. J., 2012, 18, 9955; (c) M. L. Laury, S. E. Boesch, I. Haken, P. Sinha, R. A. Wheeler and A. K. Wilson, J. Comput. Chem., 2011, 32, 2339.

22 É. Brémond, M. Savarese, N. Q. Su, Á. J. Pérez-Jiménez, X. Xu, J. C. Sancho-García and C. Adamo, J. Chem. Theory Comput., 2016, 12, 459.

23 Y. Zhao and D. G. Truhlar, Theor. Chem. Acc., 2008, 120, 215.

24 R. Peverati and D. G. Truhlar, J. Phys. Chem. Lett., 2011, 2, 2810.

25 J.-D. Chai and M. Head-Gordon, Phys. Chem. Chem. Phys., 2008, 10, 6615.

26 A. V. Marenich, C. J. Cramer and D. G. Truhlar, J. Phys. Chem. $B, 2009,113,6378$.

27 G. Mazzeo, E. Giorgio, R. Zanasi, N. Berova and C. Rosini, J. Org. Chem., 2010, 75, 4600.

28 F. Lipparini, F. Egidi, C. Cappelli and V. Barone, J. Chem. Theory Comput., 2013, 9, 1880.

29 (a) N. Berova and K. Nakanishi, Exciton Chirality Method: Principles and Application, in Circular Dichroism: Principles and Applications, ed. K. Nakanishi, N. Berova and R. W. Woody, Wiley-VCH, New York, 2nd edn, 2000, ch. 12, p. 337; (b) N. Harada, K. Nakanishi, and N. Berova, Electronic CD Exciton Chirality Method: Principles and Applications, in Comprehensive Chiroptical Spectroscopy, ed. N. Berova, P. L. Polavarapu, K. Nakanishi, and R. W. Woody, John Wiley and Sons, New York, 2012, vol. 2, ch. 4, p. 115.

30 J.-J. Aaron, A. Tine, C. Villiers, C. Párkányi and D. Bouin, Croat. Chem. Acta, 1983, 56, 157.

31 T. Yanai, D. Tewand and N. Handy, Chem. Phys. Lett., 2004, 393, 51.

32 (a) M. Meazza, M. Kamlar, L. Jašíková, B. Formánek, A. Mazzanti, J. Roithová, J. Veselý and R. Rios, Chem. Sci., 2018, 9, 6368; (b) G. Di Carmine, D. Ragno, O. Bortolini, P. P. Giovannini, A. Mazzanti, A. Massi and M. Fogagnolo, 
J. Org. Chem., 2018, 83, 2050; (c) M. Mancinelli, S. Perticarari, L. Prati and A. Mazzanti, J. Org. Chem., 2017, 82, 6874; (d) M. Meazza, M. E. Light, A. Mazzanti and R. Rios, Chem. Sci., 2016, 7, 984; (e) P. Gunasekaran, S. Perumal, J. Carlos Menéndez, M. Mancinelli, S. Ranieri and A. Mazzanti, J. Org. Chem., 2014, 79, 11039.

33 In Gaussian 16 the BH\&HLYP functional has the form: $0.5 \times$ $E_{\mathrm{X}}^{\mathrm{HF}}+0.5 \times E_{\mathrm{X}}^{\mathrm{LSDA}}+0.5 \times \Delta E_{\mathrm{X}}^{\mathrm{Becke} 88}+E_{\mathrm{C}}^{\mathrm{LYP}}$.

34 (a) C. E. Check and T. M. Gilbert, J. Org. Chem., 2005, 70, 9828; (b) M. D. Wodrich, C. Corminbouef and P. v. R. Schleyer, Org. Lett., 2006, 8, 3631; (c) P. R. Shreiner, A. A. Fokin, J. R. A. Pascal and A. De Mejere, Org. Lett., 2006, 8, 3635; (d) S. Grimme, Angew. Chem., Int. Ed., 2006, 45, 4460; (e) Y. Zhao and D. G. Truhlar, Org. Lett., 2006, 8, 5753; (f) P. R. Shreiner, Angew. Chem., Int. Ed., 2007, 46, 4217; $(g)$ M. D. Wodrich, C. S. Wannere, Y. Mo,
P. D. Jarowski, K. N. Houk and P. v. R. Schleyer, Chem.Eur. J., 2007, 13, 7731; (h) Y. Zhao and D. G. Truhlar, Acc. Chem. Res., 2008, 41, 157; (i) T. Schwabe and S. Grimme, Acc. Chem. Res., 2008, 41, 569; (j) M. D. Wodrich, D. F. Jana, P. v. R. Schleyer and C. Corminbouef, J. Phys. Chem. A, 2008, 112, 11495.

35 D. Padula, L. Di Bari and G. Pescitelli, J. Org. Chem., 2016, 81, 7725.

36 T. Bruhn, A. Schaumlöffel, Y. Hemberger, and G. Pescitelli, SpecDis, Version 1.71, Berlin, Germany, 2017, https:// specdis-software.jimdo.com.

37 R. Berardozzi, C. A. Guido, M. A. M. Capozzi, C. Cardellicchio, L. Di Bari and G. Pescitelli, Eur. J. Org. Chem., 2015, 5554.

38 GaussView 6.0.16, Semichem Inc, 2016. 